Sādhanā Vol. 37, Part 5, October 2012, pp. 569-577. (C) Indian Academy of Sciences

\title{
Effect of solid lubricants on friction and wear behaviour of alloyed gray cast iron
}

\author{
ARAVIND VADIRAJ $^{\mathrm{a}, *}$, M KAMARAJ $^{\mathrm{b}}$ and V S SREENIVASAN ${ }^{\mathrm{a}}$ \\ a Advanced Engineering Department, Ashok Leyland Technical Centre, \\ Vellivoyalchvadi, Chennai 600103, India \\ ${ }^{b}$ Metallurgical and Materials Engineering Department, Indian Institute \\ of Technology Madras, Chennai 600036, India \\ e-mail: Aravind.Vadiraj@ashokleyland.com; aravindmail@yahoo.com
}

MS received 25 January 2011; revised 22 August 2011; accepted 19 October 2011

\begin{abstract}
Friction and wear behaviour of $\mathrm{MoS}_{2}$, boric acid, graphite and $\mathrm{TiO}_{2}$ at four different sliding speeds $(1.0,1.5,2.0,2.5 \mathrm{~m} / \mathrm{s})$ has been compared with dry sliding condition. $\mathrm{MoS}_{2}$ and graphite show 30 to $50 \%$ reduction in mass loss compared to other lubricants at all sliding speeds. Friction coefficient reduces with increase in sliding speeds for all the conditions. Friction coefficient of dry as well as lubricant coated samples varies from 0.2 to 0.55 with $\mathrm{MoS}_{2}$ showing the lowest value (0.2). Boric acid and $\mathrm{TiO}_{2}$ coated samples show high friction coefficients at higher sliding speeds due to poor lubricity and adherence. This could also be due to sliding resistance offered by lubricant coated samples with predominant asperities interaction. $\mathrm{MoS}_{2}$ and graphite coated samples also generated lowest frictional temperature compared to other conditions.
\end{abstract}

Keywords. Solid lubricants; wear; friction; boundary lubrication.

\section{Introduction}

Many automotive components are made from gray cast iron which is known for its excellent properties such as good thermal conductivity, good machinability, vibration damping capacity along with good mechanical strength and wear resistance. Gray cast iron contains ferriticpearlitic or fully pearlitic matrix with graphite flakes randomly dispersed in the matrix. Therefore, it is suitable for components such as piston rings, engine liners, clutch and brake systems. Additions of alloying elements or heat treatments will improve their properties much beyond the conventional gray cast irons. Alloying elements would tend to strengthen the matrix, refine the microstructure or introduce hard phases in the matrix to impart suitable properties required for specific applications. For example, $\mathrm{Si}$ is a strong graphitizer and $\mathrm{Mn}$ is a pearlite stabilizer. Ni

*For correspondence 
and $\mathrm{Cu}$ add strength to the matrix and $\mathrm{Mo}$ and $\mathrm{Cr}$ form respective carbides to impart wear resistance. Dry sliding friction and wear behaviour of hypereutectic and hypoeutectic alloyed gray cast irons in as-cast and austempered conditions have been studied earlier (Vadiraj et al 2009a, b, c; 2010a, b, c). It is reported that addition of alloying imparts adequate mechanical strength to the matrix while significantly improving their wear properties (Vadiraj et al 2009a, b, c; 2010a, b, c). Heat treatments such as austempering can bring about much higher improvements in their wear properties compared to pearlitic irons at comparable strength (Vadiraj et al 2009a, b, c; 2010a, b, c).

Piston rings in an internal combustion engines experiences lubricant starved condition at the ends of their stroke length. Unlike hydrodynamic lubrication where the lubricant film completely separates the mating surface, boundary lubrication is characterized by the absence of lubricants at the contact where surface interaction leads to severe form of wear. The lubricant film thickness goes below the roughness peaks in boundary lubrication regime leading to dry sliding behaviour. The dominant wear modes prevalent during boundary regime are adhesive, abrasive, surface fatigue and chemical wear. The debris that is generated from dry sliding also further aggravates the wear of parts.

The presence of oil additives can possibly provide some reduction in friction and wear of sliding contact. Every grade of industrial lubricants normally comes with several additive components which would physically or chemically absorb on the surface to prevent aggressive wear condition in boundary lubrication regime. Solid lubricants in sufficient thickness can effectively work under extreme conditions of temperature, loads and speeds. Layered solid lubricants (boric acid, molybdenum disulphide and graphite) reduce friction by the mode of easy shear between their layers. They can be applied through buffing, sputter coating or as composite films on the sliding surfaces.

Molybdenum disulphide $\left(\mathrm{MoS}_{2}\right)$ is a good example of layered solids with friction coefficient less than 0.05 in dry condition (Vadiraj \& Kamaraj 2009). Fullerene structures can withstand very high loads and speed (Huang et al 2005). But they also oxidize beyond $450^{\circ} \mathrm{C}$ and become ineffective. Coated films are reported to greatly improve the scuffing resistance (Martins et al 2008; Amaro et al 2005). Relative humidity is known to affect the friction and wear behaviour of $\mathrm{MoS}_{2}$ (Steinmann et al 2004).

Boric acid $\left(\mathrm{H}_{3} \mathrm{BO}_{3}\right)$ is known for its excellent lubricity. It is an environmental friendly substance with layered morphology similar to graphite. Boric acid additive in a metal working fluid has shown very low wear and friction of parts (Rao \& Xie 2006; Rao \& Wei 2001). Wear tracks observed after sliding with boric acid additive show layered crystallites aligned parallel to the tracks to lower the friction (Erdemir et al 1990). A boric oxide coating can also generate boric acid layer in atmosphere under humid conditions to produce lubricious effect (Hu et al 2007; Deshmukha et al 2006). Transmission fluid with boric acid suspension reduces friction and wear to considerable extent (Yun-tao et al 2008).

Graphite is a well-known solid lubricant with lamellar morphology used in all the industrial lubrication system. It is available in the form of amorphous, natural and synthetic grades. It needs moisture for good lubricity. Graphite blends and pure graphite dry film is widely used for applications such as hot and cold forming, wire drawing and billet coatings, on high-speed cutting tools, as a mold release for die casting process, plastic and rubber mold applications, cylinder head and exhaust bolts, ammunition and armament applications, automotive engine and many common industrial applications.

Titanium dioxide is an environmental friendly material which does not have lamellar morphology like other solid lubricants mentioned earlier. But nano $\mathrm{TiO}_{2}$ particle suspended in $\mathrm{SAE} 30$ grade oil gave the best friction performance $(\mathrm{COF}<0.1)$ comparable to $\mathrm{CuO}$ below 
$353 \mathrm{~K}\left(80^{\circ} \mathrm{C}\right.$ ) (Wu et al 2007). Therefore, an attempt has been made to compare the friction performance of commercially available titanium dioxide with other lamellar solids.

Alloyed gray cast iron was selected as the substrate in this work since it is traditionally used as piston rings or engine sleeves/liners in most of the automobiles engines. The friction and wear performance of four solid lubricants $\left(\mathrm{MoS}_{2}\right.$, graphite, boric acid and $\left.\mathrm{TiO}_{2}\right)$ has been compared in this work. These lubricants were applied on the dry surface and the effect of sliding speed on their friction and wear performance has been investigated in depth. This is to simulate the worst possible dry condition frequently experienced by sliding parts of industrial machineries under oil starved conditions. A correlation has been established between friction and wear with load and sliding speed.

\section{Experimental details}

Gray cast iron with certain composition $(3.43 \mathrm{C}-1.75 \mathrm{Si}-0.1 \mathrm{~S}-0.038 \mathrm{P}-0.74 \mathrm{Mn}-0.36 \mathrm{Cr}-0.41 \mathrm{Cu})$ was melted in a $150 \mathrm{~kg}$ induction furnace. $\mathrm{Ni}$, $\mathrm{Mo}$ and $\mathrm{Cu}$ were added to the melt to get the alloyed gray iron with the desired composition $(3.44 \mathrm{C}-2.02 \mathrm{Si}-0.64 \mathrm{Mn}-0.64 \mathrm{Ni}-0.37 \mathrm{Cr}-$ $0.35 \mathrm{Mo}-0.57 \mathrm{Cu}-0.12 \mathrm{~S}-0.07 \mathrm{P})$. All the values of composition are in weight percentage. The melt was cast in a sand mold. The microstructures were observed in an optical microscope. The hardness was estimated with Brinell hardness testing machine.

The cast bars were machined and tensile properties were tested according to ASTM E8 standard. Wear studies were conducted with a pin-on-disc test rig designed according to ASTM G99-05 standard. Wear pins were $9 \mathrm{~mm}$ in diameter with a length of $15 \mathrm{~mm}$. Disc was a through hardened $\mathrm{Cr}$ steel with composition (in wt. \%): $1.08 \mathrm{C}-1.34 \mathrm{Cr}-0.4 \mathrm{Mn}-0.38 \mathrm{Si}-0.026 \mathrm{P}-0.046 \mathrm{~S}$. The average hardness of the disc was $752 \mathrm{VHN}$ at $2 \mathrm{~kg}$ normal load. The average surface roughness was $4 \mu \mathrm{m}$.

Commercially available solid lubricants with average particle size of $0.64 \mu \mathrm{m}$ were procured. The surface of the disc was cleaned with acetone and the lubricants were burnished with a cloth on to the surface. The lubricant particles fill within the roughness valleys on the surface and simulate the layer that forms during oil starved condition. Wear test was performed at $100 \mathrm{~N}$ normal load for a fixed sliding distances of $6000 \mathrm{~m}$. Wear loss is a measurement of difference between initial and final weight after sliding for a specific fixed distance. Wear loss was measured for four different sliding speeds $(1.0,1.5,2.0$ and $2.5 \mathrm{~m} / \mathrm{s})$. Two experiments were conducted at each of the sliding speeds and the average was recorded as wear loss. Temperature profiles at small incremental loads were measured by inserting a k-type thermocouple into the sample with a blind hole reaching up to $1 \mathrm{~mm}$ from the sliding interface for both dry and lubricant coated condition.

\section{Results and discussion}

The microstructures of alloyed gray cast iron used for pins are as shown in figure 1 . The microstructure consists of complete pearlite with graphite volume of $17 \%$. The morphology corresponds to type $3 \mathrm{~A}$ class. The distinct white regions are hard carbide particles along the eutectic cell boundaries which also imparts wear resistance to the material. The alloyed cast iron had tensile strength of 300 to $350 \mathrm{MPa}$ with hardness of 210 to $240 \mathrm{BHN}$.

Mass loss at various sliding speeds with different solid lubricants is shown in figure 2. In general, the mass loss shows a slight decreasing trend for all the conditions except boric acid. $\mathrm{MoS}_{2}$ 

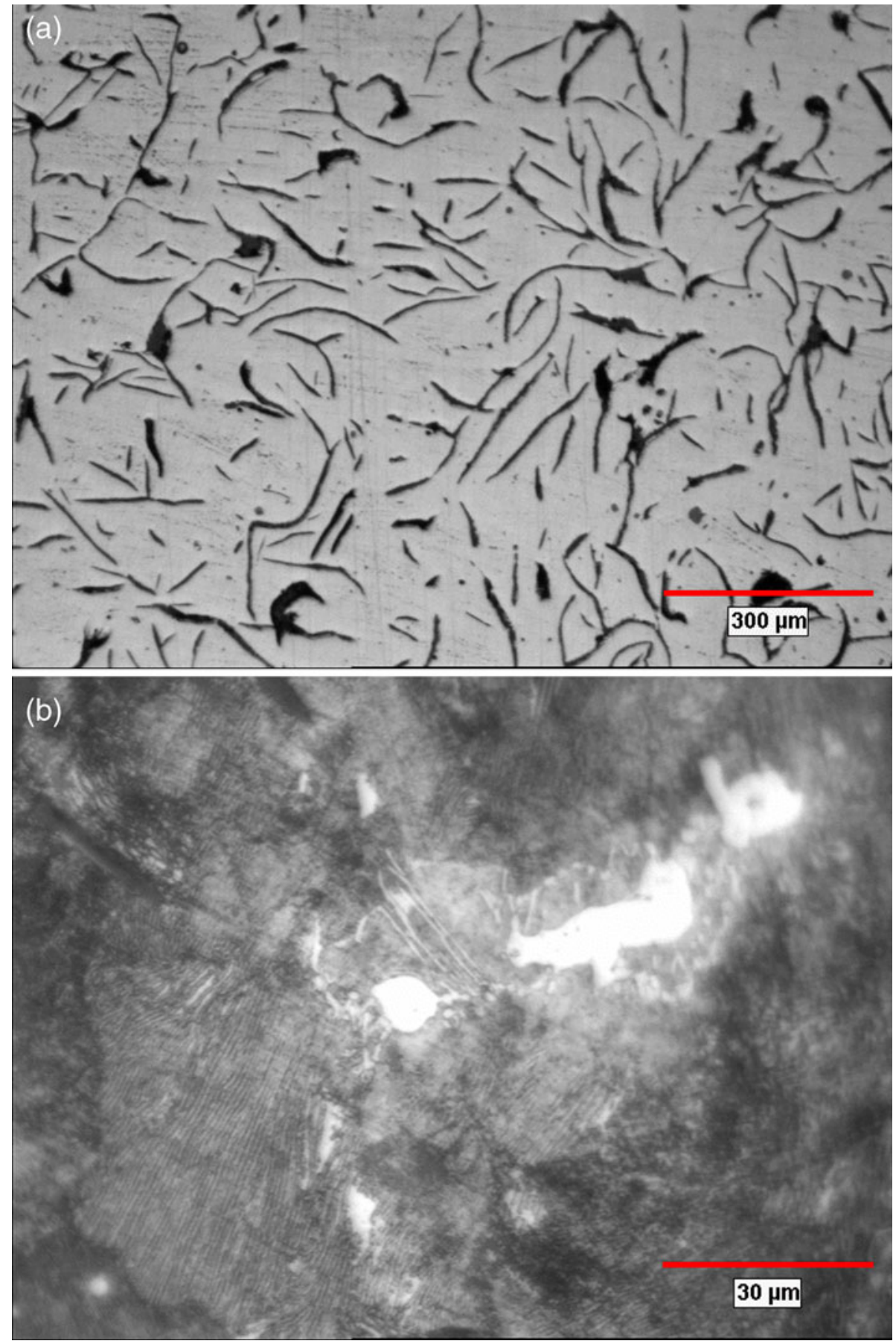

Figure 1. (a) Unetched microstructure and (b) etched microstructure of alloyed gray cast iron. 


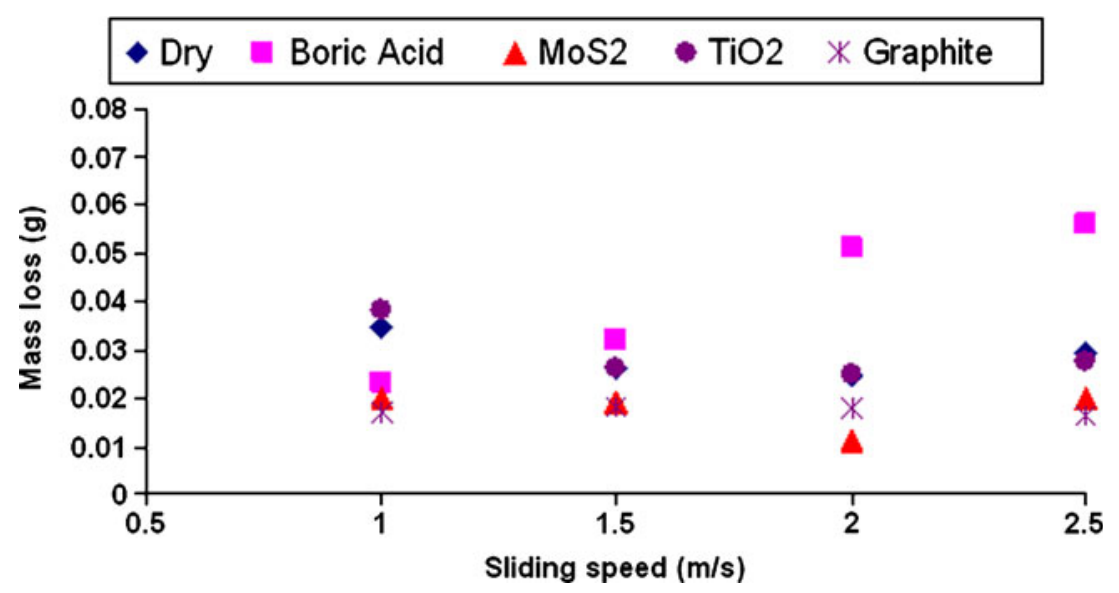

Figure 2. Mass loss at various sliding speeds for different lubricants.

and graphite have shown slightly reduced wear compared to dry and other lubricants. It is about 30 to $50 \%$ less than others with few exceptions. Graphite has been traditionally used as lubricants for many applications. The two important selection parameters are purity and crystallite size. Graphite suspension in a mineral oil shows reduction in wear rate (TIMCAL, 2004). It is reported that the wear rate decreases with increase in crystallite size and increases with increase in impurity content. Synthetic grades show lower wear rate compared to natural grades. Graphite and $\mathrm{MoS}_{2}$ blends have also shown the reduction in wear rate. The effect is more pronounced at higher loads. It is reported that graphite has the best thermal stability and fade resistance in the presence of $\mathrm{Sb}_{2} \mathrm{~S}_{3}$ with consistent friction performance in an automotive brake material (Min et al 2006). The presence of graphite alone will induce early fading of the material. But the blend of lubricants has shown better performance. A composite coating on phosphated steel consisting of graphite $(25 \%)$, zirconia $(8 \%)$ and $\mathrm{MoS}_{2}$ has significantly improved the wear resistance (72\%) and decreased COF from 0.11 to 0.06 . (Shankara et al 2008).

Boric acid has shown higher wear loss at higher sliding speeds. This is possibly due to chemical conversion of boric acid to boric oxide which takes place at $443 \mathrm{~K}\left(170^{\circ} \mathrm{C}\right)$ at higher sliding speeds due to friction-induced interfacial temperature. The temperature may be high enough to prevent any reverse conversion of boric oxide to boric acid even in the humid atmospheric condition. The boric oxide formed may be more abrasive than dry condition. As thick films and at mild operating conditions, boric acid may be good enough to protect the surface. But at higher loads and speeds, the same could be abrasive as it has shown wear loss higher than even dry condition. $\mathrm{TiO}_{2}$ has shown wear loss similar to dry condition. It may work well as nano particles suspensions in base oil (Wu et al 2007). But under extremely dry condition, it may not be effective.

The trend of friction coefficient with respect to sliding speed for different solid lubricants has been shown in figure 3. Generally, friction reduces with increase in sliding speed (from 0.40.55 to $0.25-0.35)$ possibly from temperature-induced softening and reorientation of lubricant layers parallel to substrate. The lubricant film containing lumps of particles may disintegrate from the influence of higher temperature and shear force and reorients itself along the sliding plane to reduce friction. Friction values are way higher compared to literature values because the lubricants are stored below the roughness peaks and solid surface interactions do take place under this condition. In the oil starved conditions, the solid additives within the oil come into 


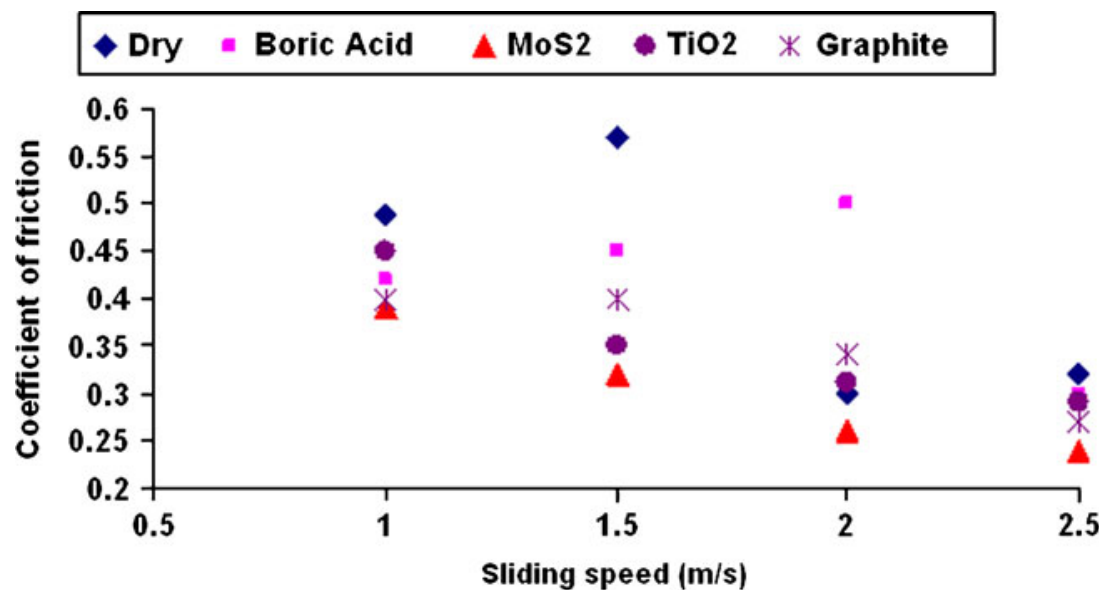

Figure 3. Friction coefficient at various sliding speeds for different lubricants.

operation and reduces friction and wear. But it is not as effective as solid low friction films coated through different process such as PVD or spray coatings. This work simulates the natural process of operation in the lubricated sliding parts of a typical machine.

$\mathrm{MoS}_{2}$ has shown less frictional force compared to other lubricants. Even at the highest sliding speed $(2.5 \mathrm{~m} / \mathrm{s})$ the reduction in frictional losses indicates that the $\mathrm{MoS}_{2}$ layer has good adherence to the substrate and does not under go any chemical conversion. Dry and boric acid coated samples have shown erratic but decreasing trend. $\mathrm{TiO}_{2}$ has shown friction losses slightly less than dry condition at lower sliding speeds. It is also ineffective at higher speeds. Friction may also be influenced by the compacted mixture of debris and lubricant within the surface crevices. It is possible that mixture generates higher friction than dry condition by offering higher resistance to sliding as impediments. It is a complex dynamic interaction of several variables and cannot be captured by single and simple models. But the effect is felt to some extent from the results obtained. The mixture layer formed may protect or quickly erode from the surface depending upon its size, nature and adherence to the substrate.

The friction coefficient with respect to incremental loading steps for different lubricants is shown in figure 4 . Two points shown for a single lubricant condition indicate maximum and minimum values. In general, frictional force remains steady within a specific range for a specific sliding speed. But it decreases with sliding speed as observed earlier (figure 2). The scatter is higher at lower loads $(<30 \mathrm{~N})$ possibly due to lubricants retained as coarse particles rather than re-oriented layers parallel to the sliding direction. $\mathrm{MoS}_{2}$ and graphite are particularly effective even in this range of loading. However, there are few exceptions. The scatter slowly reduces due to reorientation of lubricants parallel to substrate as said earlier with incremental load steps. Higher loads possibly help break up the particulate like lubricants to finer parallel layers. Slight differences in friction coefficient values are observed even at higher loads indicating the effectiveness of lubricants possessing higher load carrying ability.

The friction coefficients for different lubricants at various sliding speeds are shown in figure 5 . Even here, it is observed that the friction coefficient values lie within a specific range for all the lubricants. Lowest sliding speed $(1 \mathrm{~m} / \mathrm{s})$ shows the highest value due to impediments from coarse particulate-like lubricant layer. The friction coefficient values gradually reduce with increase in sliding speeds from the lubricant particle fragmentation and re-orientation as described earlier. 


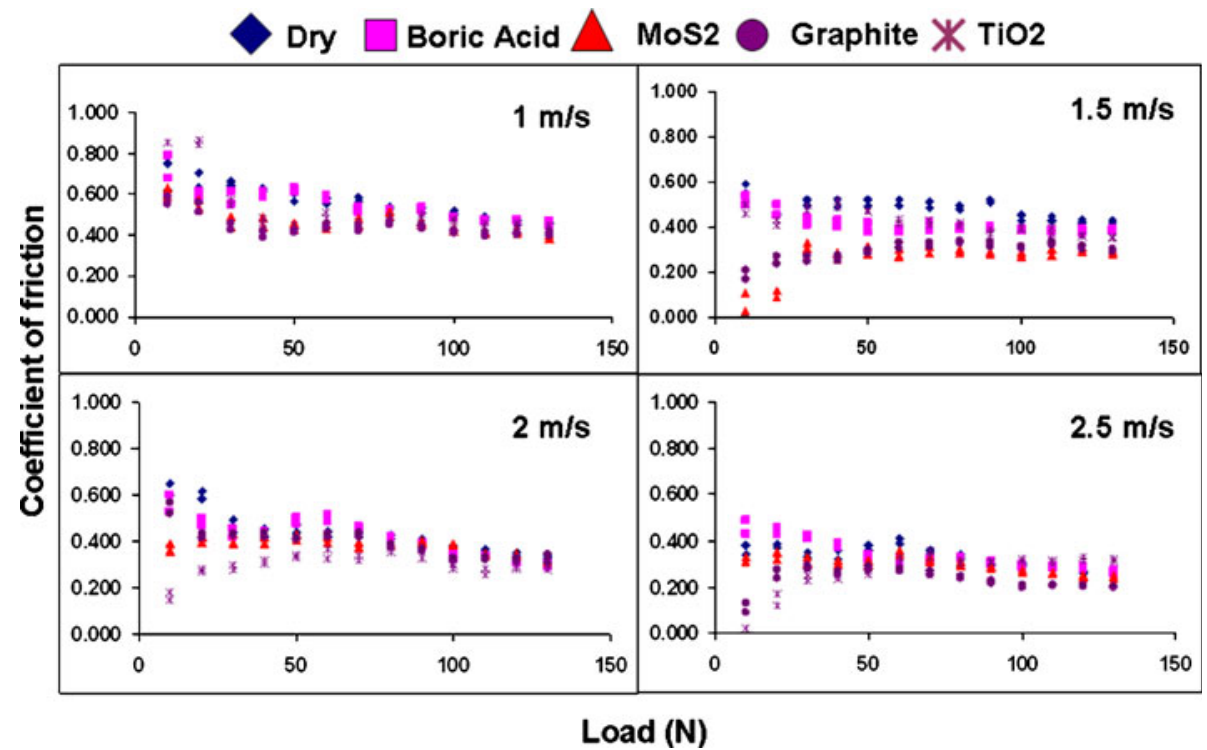

Figure 4. Variation of coefficient of friction at incremental load for various lubricants and sliding speeds.

A mild decreasing trend is observed in case of dry and boric acid lubricated sample although by and large the values are within a specific range (0.3-0.5).

Temperature profiles generated near the sliding interface for incremental loading steps and sliding speeds are shown in figure 6. Higher sliding speeds have generated higher temperature than lower speed. It is clearly evident that samples coated with $\mathrm{MoS}_{2}$ and graphite has generated significantly less temperature compared to other conditions. This is due to their excellent lubricity and adherence. With the increase in sliding speeds, it is also observed that boric acid and $\mathrm{TiO}_{2}$ coated samples have generated temperature equal to or higher than dry condition. This

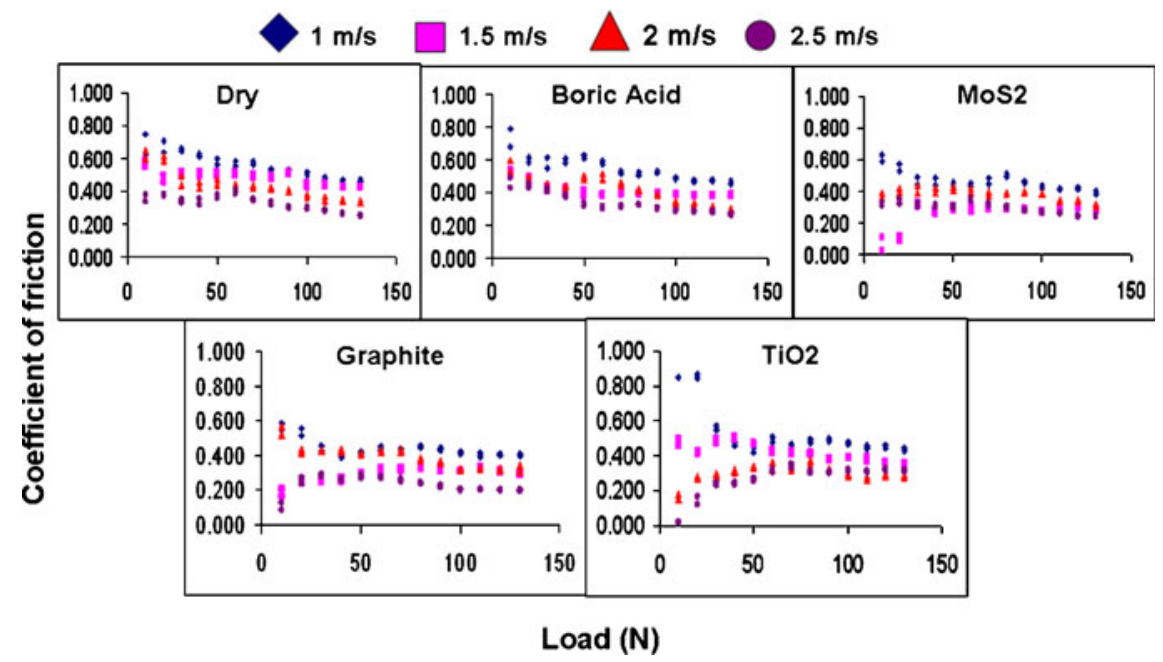

Figure 5. Variation of coefficient of friction at incremental load for various lubricants and sliding speeds. 


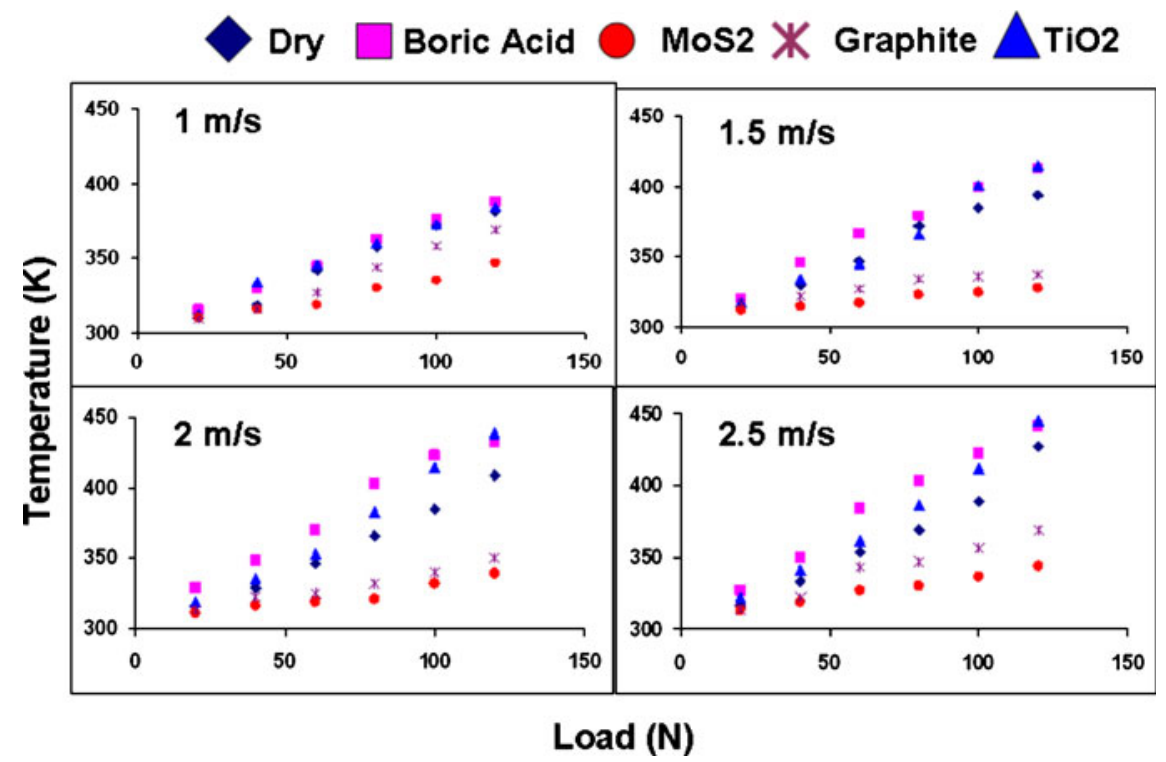

Figure 6. Temperature profile at incremental loading steps for different sliding speeds and lubricants.

is due to poor lubricity and adherence as mentioned earlier. The differences are small at lower loads while it markedly differs with increasing load. This indicates with gradual increase in normal load, the frictional force also increases proportionately. Different trends have been observed for different lubricants. Boric acid and $\mathrm{TiO}_{2}$ coated sample show slightly higher temperature at higher sliding speeds. This is possibly due to increase in resistance to sliding because of the presence of mixture of debris and lubricants.

\section{Conclusions}

The effect of sliding speeds on friction and wear behaviour of $\mathrm{MoS}_{2}$, boric acid, $\mathrm{TiO}_{2}$ and graphite has been compared with dry condition. Results indicate that $\mathrm{MoS}_{2}$ and graphite show 30 to $50 \%$ reduction in mass loss compared to other lubricants at all sliding speeds. The friction coefficient reduces with increase in sliding speed for all the condition possibly due to higher temperature and shear force causing reorientation of lubricant layers. Higher wear and friction coefficient values experienced by boric acid layer are possibly due to conversion of boric acid to abrasive boric oxide. $\mathrm{TiO}_{2}$ showed similar friction and wear trends as dry condition. Sliding interface temperature increases with increase in sliding speed. $\mathrm{MoS}_{2}$ and graphite show lowest temperature profiles due to good lubricity and adherence to the surface. Boric acid and $\mathrm{TiO}_{2}$ are as good as in dry condition due to poor lubricity and adherence to the surface.

\section{Acknowledgements}

The authors would like to thank Dr. Sathya Prasad and Mr. Jayendra Parikh, of Advanced Engineering Department Ashok Leyland Technical Centre, for their support in the research work. 


\section{References}

Amaro R I, Martins R C, Seabra J O, Renevier N M and Teer D G 2005 Molybdenum disulphide/titanium low friction coating for gears application, Tribol. Int., 38(4): 423-434

Deshmukha P, Lovell M, Sawyer G W, Mobley A 2006, On the friction and wear performance of boric acid lubricant combinations in extended duration operations, Wear, 260: 1295-1304

Erdemir A, Frenske G R, Erck R A 1990 A study on the formation and self lubrication mechanisms of boric-acid films on boric oxide coatings, Surf. Coat. Technol., 43: 588-596

Hu Z-B, Li H-J, Fu Q-G, Xue H, Sun G-L 2007 Fabrication and tribological properties of $\mathrm{B}_{2} \mathrm{O}_{3}$ as friction reducing coatings for carbon-carbon composites, New Carbon Materials, 22(2): 131-134

Huang H D, Tu J P, Zou T Z, Zhang L L and He D N 2005 Friction and wear properties of IF-MoS 2 as additive in paraffin oil, Tribol. Lett. 20(3-4): 247-250

Martins R, Amaro R, Seabra J 2008 Influence of low friction coatings on the scuffing load capacity and efficiency of gears, Tribol. Int. 41(4): 234-243

Min H C, Jeong J, Seong J K, Ho J 2006 Tribological properties of solid lubricants (graphite, $\mathrm{Sb}_{2} \mathrm{~S}_{3}, \mathrm{MoS}_{2}$ ) for automotive brake friction materials, Wear, 260: 855-860

Rao K P, Xie C L 2006 A comparative study on the performance of boric acid with several conventional lubricants in metal forming processes, Tribol. Int. 39: 663-668

Rao K P, Wei J J 2001 Performance of a new dry lubricant in the forming of aluminum alloy sheets, Wear, 249: 86-93

Shankara A, Pradeep L M, Simha K R Y, Satish V K 2008 Study of solid lubrication with MoS2 coating in the presence of additives using reciprocating ball-on-flat scratch tester, Sadhana, 33(3): 207-220

Steinmann A M, Meerkamm H 2004 A new type of tribological coating for machine elements based on carbon, molybdenum disulphide and titanium diboride, Tribol. Int. 37(11-12): 879-885

TIMCAL Ltd. 2004 Test report on graphite and carbon, Bodio, Switzerland

Vadiraj A, Balachandran G, Kamaraj M 2009a Effect of misch metal inoculation on mechanical and wear properties of hypoeutectic gray cast iron, J. Materials and Design, 30(10): 4488-4492

Vadiraj A, Balachandran G, Kamaraj M, Gopalakrishna B, Venkateswara Rao D 2009b Mechanical and Wear behavior of alloyed hypereutectic gray cast iron, Mater. Sci. Technol., DOI: 10.1179/026708309X12454008169429

Vadiraj A, Balachandran G, Kamaraj M 2009c Structure and property studies on austempered and as-cast ausferritic gray iron, J. Mater. Eng. Perform., DOI: 10.1007/s11665-009-9566-8

Vadiraj A, Balachandran G, Kamaraj M, Gopalakrishna B, Venkateswara Rao D 2010a Wear behavior of hypereutectic gray cast iron, Tribol. Int., 43(3): 647-653

Vadiraj A, Balachandran G, Kamaraj M, Gopalakrishna B, Prabhakara Rao K 2010b Structure property correlation of austempered alloyed hypereutectic gray cast iron, Mater. Sci. Eng. A, 527: 782-788

Vadiraj A, Balachandran G, Kamaraj M, Gopalakrishna B, Prabhakara Rao K 2010c Studies on mechanical and wear properties of alloyed hypereutectic gray cast irons in the as-cast pearlitic and austempered conditions, J. Materials and Design 31: 951-955

Vadiraj A, Kamaraj M 2009 Comparative wear analysis of $\mathrm{WS}_{2}$ and $\mathrm{MoS}_{2}$ dry lubricant coatings on plasma nitrided SG iron, J. Mater. Eng. Perform., DOI: 10.1007/s11665-009-9432-8

Wu Y Y, Tsui W C, Liu T C 2007 Experimental analysis of tribological properties of lubricating oils with nanoparticle additives, Wear, 262: 819-825

Yun-tao X, Dao-xin L, Dong H 2008 Improvement of corrosion and wear resistances of AISI 420 martensitic stainless steel using plasma nitriding at low temperature, Surf. Coat. Technol., 202(12): $2557-2583$ 